\title{
Calcium Hydroxide-Based Degradation of Hydrocarbons in Petroleum Refinery Wastewater
}

\author{
Khedidja Benouis ${ }^{1, *}$ Yasmina Khane ${ }^{2,3}$ Yassine Khalfi ${ }^{1}$ Soufiane \\ Guella ${ }^{1}$ Amine Chalabi ${ }^{4}$ \\ ${ }^{1}$ Laboratory of Process Engineering, Materials and Environment, faculty of Technology, University of Djillali \\ Liabes, PO Box 89, Sidi Bel Abbes 22000 -Algeria. \\ ${ }^{2}$ Université de Ghardaia, B.P 455, Ghardaïa, Algerie \\ ${ }^{3}$ Laboratory of Applied Chemistry, ACTR Univ Ain Temouchent, PO Box 284, Ain Temouchent 46000 -Algeria. \\ ${ }^{4}$ Department of mechanical engineering, faculty of Technology, University of Djillali Liabes, PO Box 89, Sidi Bel \\ Abbes 22000 -Algeria. \\ "Corresponding author. Email: benouis_khadidja@yahoo.fr
}

\begin{abstract}
Hydrocarbons, aldehydes, sulfides, heavy metals, and other contaminants from petroleum treatment processes have been discovered in the oil and gas industry liquid discharge. Hydrocarbons primarily cause the pollution shared by all units. The purpose of this study is to assess the performance of the coagulation-flocculation process in the primary treatment stage for the removal of hydrocarbons and turbidity from the effluent of the Algerian oil refinery RA1/Z. Using $1 \mathrm{~g} / \mathrm{L}$ of calcium hydroxide coagulant and operating at a stirring speed of $100 \mathrm{rpm}$ for 3 minutes, an excellent elimination of $95.1 \%$ and $90.4 \%$, respectively, of turbidity and hydrocarbons, was achieved.
\end{abstract}

Keywords: Petroleum Refinery, Effluent, Hydrocarbons, Process, Coagulation.

\section{INTRODUCTION}

Water is widely used in the industrial environment for various applications that generate gaseous and liquidemissions, the composition of which contains all kinds of organic and inorganic pollutants, whose impact on public health and the environment is significant. This generated wastewater must be treated and purified before being released into receiving environments, which are generally aquatic environments [1]. The petroleum industries are considered among the most polluting to the sea and oceans because they consume large amounts of water and reject a large portion of it which is highly polluted by substances such as hydrocarbons [2] and phenolic compounds [3]. To preserve aquatic life and to comply with discharge standards, these effluents must be purified before being rejected into the sea.

At the discharge wastewater treatment plants, the treatment methods are classified into three categories: Primary treatment consists of physical operation andseparation such as screens, gravity separation, and floatation for oil elimination. Secondary treatment aims to reduce the contamination level of effluent using chemical processes such as coagulation, flocculation, and biological. Tertiary treatment includes adsorption, filtration, and advanced oxidation processes [4]. Thechoice of purification process varies according to the type of pollution generated in order to eliminate or minimize pollution and ensure compliance with environmental quality standards. Researchers are interested in the study, development, and optimization of the various 
applied processes. Sellami et al. [5] studied the removal of turbidity, SS, hydrocarbons, and organic matter expressed as CODand $\mathrm{BOD}_{5}$ by the process of coagulation flocculation. A solution of activated silicates prepared on the basis of a mixture of sodium silicates and different percentages of citric and ascorbic acids was used as a coagulant and kurifix as a flocculent. The best result was obtainedusing $12 \mathrm{ml}$ of $4 \%$ activated silicate coagulant solution containing $2 \%$ ascorbic acid. The reduction of turbidity, SS, hydrocarbons, COD, and $\mathrm{BOD}_{5}$ reached 91\%, 87\%, 97\%, 85\%, and $92 \%$, respectively.

Wang et al. [6] prepared biochar from activated sludge of residual petroleum and used it in a batch reactor for the treatment of liquid effluent from the petroleum refinery. Synthesized biochar exhibited interesting properties. Its application caused the formation of more substantial and stable aerobic granules 2 weeks earlier than the control. Compared to the control, its addition improved the removal efficiencyof COD, oil, and total nitrogen $(3,4$, and $10 \%)$ respectively.

Aljuboury et al. [7] optimized the operating conditions to remove COD and TOC from petroleum wastewater in Oman, using the $\mathrm{TiO}_{2} / \mathrm{Zn}$ photocatalyst involved in two methods $\left(\mathrm{TiO}_{2} / \mathrm{ZnO} /\right.$ air/Solar and $\mathrm{TiO}_{2} / \mathrm{ZnO} /$ Fenton processes). The best elimination was obtained by applying the tritemnt to $\mathrm{TiO}_{2} / \mathrm{ZnO} /$ air/solar. The optimal operating conditions were $\mathrm{ZnO}\left(5.4 .10^{4}\right.$ mg. $\left.\mathrm{L}^{-1}\right)$ and $\mathrm{TiO}_{2}\left(5.10^{4} \mathrm{mg} . \mathrm{L}^{-1}\right)$. Under these conditions, the reduction in COD and TOC reached $74 \%$ and $99 \%$, respectively.

Using response surface methodology, Singh et al. [8] optimized the parameters of the coagulation process, which is applied in the pre-treatment of petroleum wastewater. The authors evaluated the effectiveness of three metallic coagulants: $\mathrm{FeCl}_{3}$, $\mathrm{CuSO}_{4}$, and a mixture of $\mathrm{FeCl}_{3}$ and $\mathrm{CuSO}_{4}$ (1:1). The optimized parameters were the initial $\mathrm{pH}$ of the wastewater and the dose of the coagulant. The impacts on the final $\mathrm{pH}$ and the reduction of DOC, turbidity, TDS, and color were studied. The results showed that the $\mathrm{FeCl}_{3}+\mathrm{CuSO}_{4}$ mixture gave better results compared to $\mathrm{FeCl}_{3}$ and $\mathrm{CuSO}_{4}$ individually. The maximum elimination was noted at a $\mathrm{pH}$ of 7.1 and at a dosage of $200 \mathrm{mg} . \mathrm{L}^{-1}$ of mixed coagulant. In aqueous solutions, and using phytochemical treatment with $\mathrm{VUV} / \mathrm{H}_{2} \mathrm{O}_{2}$ and $\mathrm{UV} / \mathrm{H}_{2} \mathrm{O}_{2}$ at 185 and 254nm, respectively, Bustillo et al. [9] studied the degradation of Benzene, Toluene, Ethylbenzene, and Xylenes, molecules detected in petrochemical wastewater. It has been observed that the concentration of 0.30 g.L $\mathrm{L}^{-1}$ and $0.25 \mathrm{~g} . \mathrm{L}^{-1}$ of $\mathrm{H}_{2} \mathrm{O}_{2}$, under UV-254 and UV-185 nm, respectively, is recommended to degrade a TOC concentration of 0.1 g.L.-1.

This work aims to study the performance of the coagulation process using calcium hydroxide for the elimination of petroleum hydrocarbons and turbidity from liquid effluent of the Arzew petroleum Refinery RA1/Z in Algeria using the coagulation flocculation was carried out using lime as a coagulant. The dosage of coagulant, the speed, and the time of coagulation were optimized in order to achieve the maximum performance of the process and ensure the maximum elimination of the hydrocarbon colloids in the secondary treatment stage of the wastewater.

\section{METHODOLOGY 2.1. Location of the study area}

The RA1/Z oil refinery is located by the sea, in the industrial zone, two kilometers from the town of Arzew and about 40 kilometers from the city of Oran in Algeria. It was built in 1972, It occupies 170 hectares and is located near the port of Arzew, allowing kidnappings by boat. The RA1/Z oil refinery is the third largest oil refinery in Algeria after those of Algiers and Hassi Messaoud. it is currently operated by SONATRACH (Algerian Company for Research, Production, Transport, Processing, and Marketing of Hydrocarbons); first african company in the field of hydrocarbons. The effluent treated came from the wastewater treatment unit (zone 27) of the RA1 / Z oil refinery, the outlet point of the API oil / water separator. The initial concentration of the hydrocarbons was $165 \mathrm{ppm}$, the turbidity was $91 \mathrm{NTU}$, and the $\mathrm{pH}$ of the water was 7.04.

\subsection{Coagulation-flocculation treatmentexperimental trials}

On a laboratory scale, the coagulation/flocculation tests were performed, at room temperature $(20 \pm$ $1.0{ }^{\circ} \mathrm{C}$ ) and using a Jar Test device (model AOUA/UTC) equipped with four stainless steel blades, whose stirring speed varies from 0 to 200 rpm while the stirring time is from 0 to $30 \mathrm{~min}$. Experiments were carried out in $600 \mathrm{ml}$ beakers, which were filled with $400 \mathrm{ml}$ of wastewater. The coagulant used is calcium hydroxide $\mathrm{Ca}(\mathrm{OH})_{2}$ (lime), a reagent well-known for its coagulant properties and low cost. The experimental process consisted of three stages:

1- Coagulation: use a strong mixture (100 rpm) for a short period of time (3 minutes) to promote contact between the wastewater's 
colloidal substances and the coagulant's molecules.

2- Flocculation: mixing at low stirring speed (20 rpm) for 20 minutes so as not to break the colloid-coagulant aggregates formed and promote the bonding of aggregates and the formation of flocs.

3- Settling: stopping stirring, the sample is left to stand for 1 hour to allow the maximum amount of flocs formed to settle.

The supernatant was then taken for analysis.

The parameters studied are: petroleum hydrocarbons, turbidity of the effluent and the final $\mathrm{pH}$. The treatment efficiency was assessed analytically and mainly by monitoring the rate of reduction of the turbidity value and the content of hydrocarbons. The abatement rate of parameter $\mathrm{X}$, expressed as a percentage, was calculated based on the following formula (Equation 1):
Abatement
X
$(\%)$
$[(1-$
$\left.\left.\left(\mathrm{X}_{\mathrm{f}}\right) / \mathrm{X}_{\mathrm{i}}\right)\right]^{* 100}$

(1)

$\mathrm{X}_{\mathrm{i}}$ : initial concentration of $\mathrm{X}$

$\mathrm{X}_{\mathrm{f}}$ : final concentration of $\mathrm{X}$

3. RESULTS AND DISCUSSION

\subsection{Determination of optimal coagulant dosage}

The dosage of the coagulant is an important factor that influences the performance of coagulation. It's defined as a value above which adding more coagulant has no significant effect on the removal efficiency. Ideally, an insufficient dose or an overdose would lead to poor flocculation performance, hence the existence of an optimal dosage of coagulant to be determined inorder to minimize the cost and achieve optimal processing performance. This concentration can be evaluated by measuring the variation in the turbidity of the effluent, which is directly related to the colloidspresent. The optimal dosage of $\mathrm{Ca}(\mathrm{OH})_{2}$ was found tobe $1 \mathrm{~g} / \mathrm{L}$ (Figure 1). At this concentration of coagulant, the best turbidity and hydrocarbons removal rates were obtained: $93,2 \%$ and $88,4 \%$, respectively. The turbidity decreased from 91 to $6.12 \mathrm{NTU}$ and the hydrocarbons content from 165 to $19.11 \mathrm{ppm}$ (see Table 1).
Table 1. Coagulation flocculation treatment results

\begin{tabular}{|c|c|c|c|}
\hline $\begin{array}{c}\text { Coagulant } \\
\text { dosage } \\
\text { (mg/L) }\end{array}$ & $\begin{array}{c}\text { Turbidity } \\
\text { (NTU) }\end{array}$ & $\begin{array}{c}\text { Hydrocarbons } \\
(\mathrm{ppm})\end{array}$ & $\begin{array}{c}\text { Final } \\
\mathrm{pH}\end{array}$ \\
\hline 0 & 91.00 & 165.0 & 7.04 \\
\hline 0.1 & 47.25 & 94.5 & 8.70 \\
\hline 0.2 & 21.94 & 54.00 & 10.40 \\
\hline 0.4 & 14.32 & 29.60 & 11.50 \\
\hline 0.6 & 7.87 & 24.40 & 12.10 \\
\hline 0.8 & 7.61 & 22.60 & 12.20 \\
\hline 1.0 & 6.12 & 19.11 & 12.28 \\
\hline 1.2 & 9.32 & 29.10 & 12.30 \\
\hline 1.4 & 13.10 & 33.70 & 12.41 \\
\hline
\end{tabular}

The elimination phenomenon occurs because the coagulating $\mathrm{Ca}(\mathrm{OH})_{2}$ particles bind to the colloidal particles, destabilizing their negative charges by neutralizing the charges that generate repulsive forces between them with the increase in size and weight of the colloid-coagulant aggregates formed which subsequently increases the rate at which they are deposited in water.

Beyond this content, and exceeding the optimal dosage of the coagulant, an increase in turbidity and hydrocarbons has occurred due to the enrichment of the medium in positive ions $\mathrm{Ca}^{2+}$. This causes excessive adsorption of the $\mathrm{Ca}^{2+}$ and reverses the charge of the particles, which then become positive. Thus, the particles would be dispersed.

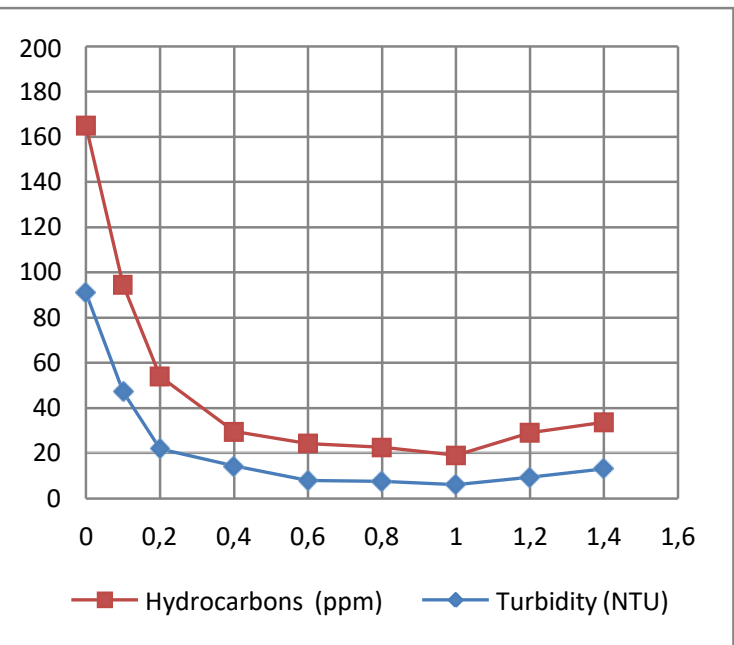

Figure 1 Variations of hydrocarbons and turbidity content as a function of coagulant dosage 


\subsubsection{Influence on the final $\mathrm{pH}$ of the wastewater}

The gradual addition of $\mathrm{Ca}(\mathrm{OH})_{2}$ to the wastewater caused a significant increase in $\mathrm{pH}$ to very basic values $(\mathrm{pH}=12)$ (Figure 2$)$. The dissociation of $\mathrm{Ca}(\mathrm{OH})_{2}$ in the waste water (Equation 2) enriches the reaction medium with $\mathrm{OH}$ ions and subsequently increases the $\mathrm{pH}$ of the water.

$\mathrm{Ca}(\mathrm{OH})_{2}+\mathrm{H}_{2} \mathrm{O} \rightarrow \mathrm{Ca}^{2+}+2 \mathrm{OH}^{-}$

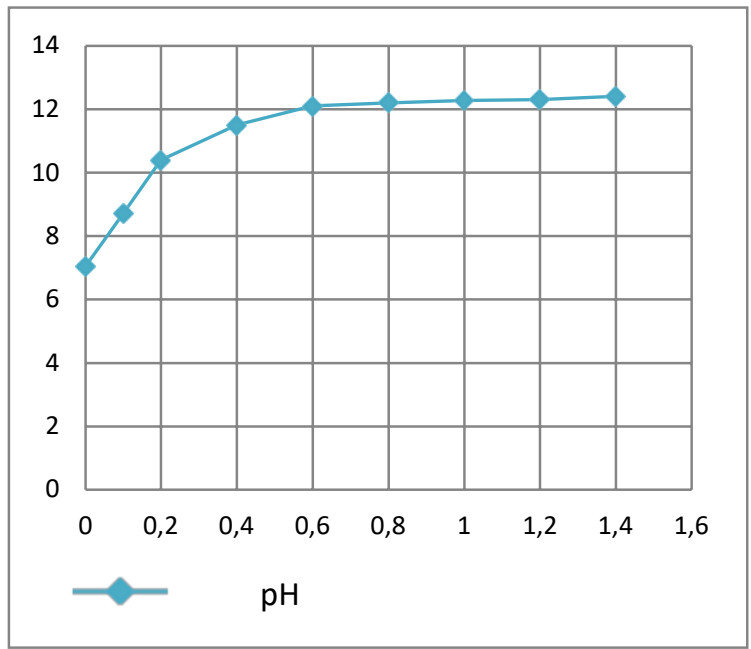

Figure 2 Variation of final $\mathrm{pH}$ of wastewater as a function of coagulant dosage

\subsection{Determination of optimal coagulation speed and time}

By setting the optimum coagulant dosage at $1 \mathrm{~g} / \mathrm{L}$, we evaluated different coagulation speeds and times:

- $100 \mathrm{rpm}$ for $3 \mathrm{~min}$ and $200 \mathrm{rpm}$ for $3 \mathrm{~min}$ : this choice was based on the fact that coagulation is a step that requires a rapid stirring speed for a short time to ensure very good diffusion of the coagulantand good chemical destabilization of the colloids.

- $50 \mathrm{rpm}$ for $3 \mathrm{~min}$ and $200 \mathrm{rpm}$ for $10 \mathrm{~min}$ : this choice was made to check the dependence betweenspeed and coagulation time. The results are listed inTable 2.
Table 2. The rate of limitation of turbidity and hydrocarbons as a function of the speed and time of coagulation

\begin{tabular}{|c|c|c|c|}
\hline $\begin{array}{c}\text { Coagulation } \\
\text { speed }\end{array}$ & $\begin{array}{c}\text { Coagulation } \\
\text { time }\end{array}$ & $\begin{array}{c}\text { Turbidity } \\
\text { removal } \\
(\%)\end{array}$ & $\begin{array}{c}\text { Hydrocarbons } \\
\text { removal (\%) }\end{array}$ \\
\hline 50 & 3 & 88 & 90 \\
\hline 100 & 3 & 90 & 95 \\
\hline 200 & 3 & 87 & 79 \\
\hline 200 & 10 & 67 & 65 \\
\hline
\end{tabular}

Stirring speed acts on the possibility of meeting the particles. It must be high enough to allow the particlesto meet. However, if it becomes too high, the flocs undergo mechanical shear, which causes their fragmentation. The results indicate that the coagulationis better at a speed of the order of $100 \mathrm{rpm}$ and for 3 minutes of time (figure 3). This means that this step can reach its optimum for a short time and at a fast but not overdone stirring speed. This efficiency decreases by increasing the time devoted to it.

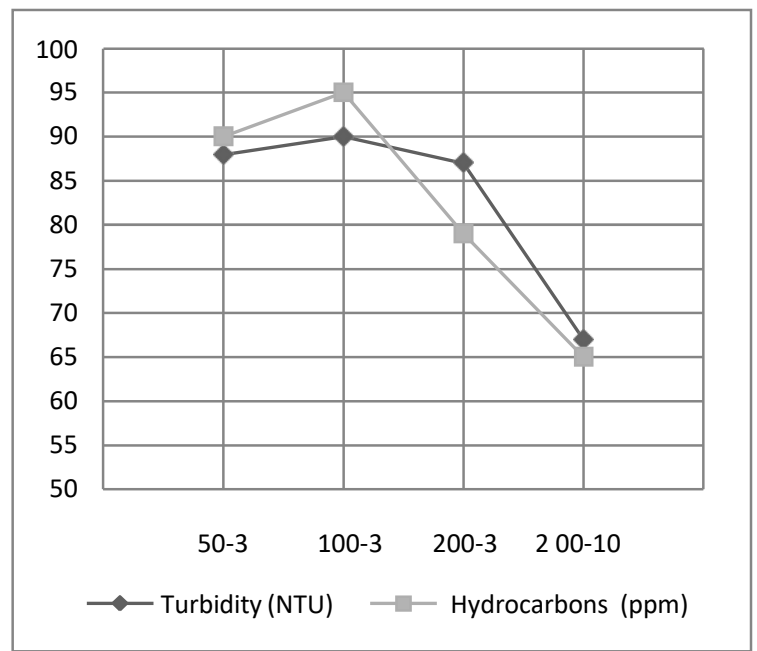

Figure 3 Variations of hydrocarbons and turbidity removal as function coagulation speed and time coagulation

\section{CONCLUSION}

The coagulation method employing calcium hydroxide $\mathrm{Ca}(\mathrm{OH})_{2}$ was investigated in this study to remove hydrocarbons and turbidity from the effluent of the Arzew oil refinery's treatment facility (Algeria).

Indeed, the most effective coagulant dosage, speed, and clotting time were discovered and 
discussed. The obtained results showed that employing $1 \mathrm{~g} / \mathrm{L}$ of coagulant and stirring at 100 rpm for 3 minutes was enough to get the process to work. The highest hydrocarbon removal rate and turbidity rates were 90.4 and $95.1 \%$, respectively, under these conditions. Indeed, the obtained results meet Algerian legislation's limit values for hydrocarbons in industrial liquid effluent emissions (10 ppm).

\section{ACKNOWLEDGMENTS}

The authors wish to thank the responsible staff of the petroleum refinery RA1/Z of Arzew in Algeria fortheir collaboration.

\section{REFERENCES}

[1] Official gazette of the democratic and popular republic of Algeria $\mathrm{N}^{\circ} 26$. Executive Decree No. 06-141 of 20 Rabie El Aouel 1427 corresponding to 19 April 2006 defining the limit values for discharges of industrial liquid effluents, 2006, pp. 4-9.

[2] S.J. Varjani, Microbial degradation of petroleumhydrocarbons, Bioresource Technology, Volume223, 2017, pp. 277-286 DOI:

https://doi.org/10.1016/j.biortech.2016.10.03 $\underline{7}$

[3] R. Singh, R.K. Dutta, D.V. Naik, A. Ray, P.K. Kanaujia, High surface area Eucalyptus wood biochar for the removal of phenol from petroleum refinery wastewater, Environmental Challenges, Volume $\quad 5, \quad 2021$

DOI:

https://doi.org/10.1016/j.envc.2021.100353

[4] S. Varjani, R. Joshi, V. K. Srivastava, H.H. Ngo,

W. Guo, Treatment of wastewater from petroleum industry: current practices and perspectives,Environ Sci Pollut Res, volume 27, 2020, pp. 27172-27180 DOI:

https://doi.org/10.1007/s11356-019-04725-X

[5] M.H. Sellami, F. Benhabireche, H. Frouhat, Chemical Treatment Process and Reuse of Oily- Waters arising from Petroleum Field of HBK/Algeria. Int J Waste Resour, Volume 6, 2017, DOI:

https://doi: 10.4172/2252-5211.1000255
[6] Wang, X., Ming, J., Chen, CM. et al. Rapid aerobicgranulation using biochar for the treatment ofpetroleum refinery wastewater. Pet. Sci. volume 17,2020, pp. 1411-1421 DOI: https://doi.org/10.1007/s12182-02000499-X

[7] D.A.A. Aljuboury, F. Shaik, Optimization of thepetroleum wastewater treatment process using $\mathrm{TiO}_{2} / \mathrm{Zn}$ photocatalyst, South African Journal ofChemical Engineering, Volume 38, 2021 DOI :

https://doi.org/10.1016/j.sajce.2021.08.001

[8] B. Singh, P. Kumar, Pre-treatment of petroleumrefinery wastewater by coagulation and flocculationusing mixed coagulant: Optimization of processparameters using response surface methodology(RSM), Journal of Water Process Engineering, Volume 36, 2020 DOI: https://doi.org/10.1016/j.jwpe.2020.101317

[9] C.F. Bustillo-Lecompte, D. Kakar, M. Mehrvar, Photochemical treatment of benzene, toluene, ethylbenzene, and xylenes (BTEX) in aqueoussolutions using advanced oxidation processes: Towards a cleaner production in the petroleum refining and petrochemical industries, Journal of Cleaner Production, Volume 186, 2018, pp. 609-617 DOI:

https://doi.org/10.1016/j.jclepro.2018.03.135

\section{NOMENCLATURE}

\begin{tabular}{|l|l|}
\hline acronym & \multicolumn{1}{c|}{ Meaning } \\
\hline $\mathrm{AC}$ & Activated Carbon \\
\hline $\mathrm{BOD}_{5}$ & 5 day Biochemical Oxygen Demand \\
\hline $\mathrm{COD}$ & Chemical Oxygen Demand \\
\hline $\mathrm{CuSO}_{4}$ & Copper Sulfate \\
\hline $\mathrm{FeCl}_{3}$ & Ferric Chloride \\
\hline $\mathrm{H}_{2} \mathrm{O}_{2}$ & Hydrogen Peroxide \\
\hline $\mathrm{PRW}$ & Petroleum Refinery Wastewater \\
\hline $\mathrm{TDS}$ & Total Dissolved Solids \\
\hline $\mathrm{TOC}$ & Total Organic Carbon \\
\hline $\mathrm{TiO} / \mathrm{Zn}$ & Titanium Dioxide/Zinc \\
\hline $\mathrm{UV}$ & Ultra Violet \\
\hline VUV & Vacuum Ultra Violet \\
\hline
\end{tabular}

